\title{
URBAN RESILIENCE - A FIRST STEP TOWARDS THE CITY OF THE FUTURE
}

\author{
Liviu Bogdan VLAD* \\ Academia de Studii Ecomonice, București, România, \\ e-mail: liviubogdanvlad@yahoo.com
}

\begin{abstract}
Citation : Vlad L. B. (2019). Urban Resilience - A First Step Towards the City of the Future. Revista Română de Geografie Politică, 21(1), 18-23. https://doi.org/10.30892/rrgp.211102-325
\end{abstract}

\begin{abstract}
As complex forms of human settlement, cities have known an unprecedented development in recent years. This has made it necessary to find new ways of preserving them during the journey they undertake. As such, policies of designing, managing, using and controling urban utility systems in general and policies of risk management in particular have begun juggling more and more often with a new concept - urban resilience. Compared to the old concept of durable urban development, urban resilience is much more comprehensive because not only does it englobe the former, but it also helps complete it with aspects regarding the management of risks associated to potential urban disturbances.
\end{abstract}

Key words: city, resilience, urban resilience, urban development, urbanism, sustainability, durable urban development

\section{INTRODUCTION}

Among the consequences of current global developments is an increase in economic, social and ecological pressure on urban systems. Changes in the global environment in recent years have made it necessary to rethink the concept of durable development and adopt a new concept - resilience, which is applicable not only to the environment, but also to other forms of territorial organization. At first, it was no easy task to use this concept in the field of urban geography because it was still an unknown element and geography was forced to work with interpretations from the field of natural sciences, while social sciences often limited themselves to simply evaluating vulnerabilities (Donovan and Oppenheimer, 2015). Over time, the concept gained momentum and started being used in both scientifical and political environments as efforts to monitor and measure urban resilience increased. Urban resilience means the optimal way of changing mentalities and of introducing prioritization in

\footnotetext{
${ }^{*}$ Corresponding Author
} 
urban development policies. The concept of urban resilience cannot be singular - it demands the connection of objectives and activities from different departments so that a common denominator can be reached with regards to the durability, viability, cohesion, robustness and development of cities. This new concept and the way it is applied in the urban space is all the more important because, in a world in constant development, the discrepancies between the rural and urban environments have become more and more clear and the preference is more and more visibly leaning towards the city, which offers its inhabitants life conditions superior to those in the rural environment. The concept in itself is a broad one, as it encompasses various types of phenomena, such as efficient functioning, efficiently adapting to less favorable conditions, overcoming shocks and normal functioning after they occur. Alongside resiliency we should emphasize security and safety and not forget that the crucial elements of this approach are citizen responsibility and the efficiency of the intervention forces.

\section{URBAN RESILIENCE, FROM CONCEPT TO REALITY}

Cities nowadays are true motors of economic development, offering opportunities and, at the same time, facing numerous problems they have to solve. Cities worldwide are trying to improve their resilience in order to be able to overcome the stress and shocks awaiting them due to global climate changes and threats of every kind. Improving resilience is all the more important as cities today are not mere isolated entities, but rather complex systems integrated in urban regions in such a way that material and human resources from much larger areas depend on them (Bogunovich, 2009). The fact that the population often shows a preference for the city - which, in comparison to the village, thus becomes economically and socially richer turns building resilient cities into one of the crucial components of urban planification. This is all the more important as only resilient cities will have the ability to survive and prosper during this period of climate change and shocks of every kind. Due to the complexity of urban systems, it is somewhat difficult to analyze urban resilience as a singular system. However, it is wellknown that more and more urban administrations consider improving resilience as one of the most important strategies on the path to development. Improving the resilience of these systems is strongly linked to the balanced development of four essential components of the system: metabolic flows, social dynamics, built space and governance networks (Resilience Alliance, 2007). Cities can be thought of as a multitude of contested spaces that generate a wide variety of urban services: transport, housing, medical assistance, work places and financial markets (Harvey, 1996). The preference for the urban environment is also a result of the essential part that cities play as centres of innovation, able to capitalize upon their potential for innovation in a variety of ways and build their own system of resilience against shocks and uncertainties. The preference for the urban environment involves a continuous growth of the population in cities, which in the $21^{\text {st }}$ century is a true challenge for sustainability. In order to withstand the challenges it faces, the city often is in need of finding solutions to the risks and threats it is confronted with on a daily basis. The most practical solution is urban resilience, which proves to be the only method of analyzing the risks and major threats that urban systems face. As such, in the public, local and 
central administration, the concept of resilience has recently become an imperative of the governance and territorial administration policies. This is especially due to the shift from planning on the basis of scientific progress, an approach of the 60's and 70's, to planning for an unexpected and uncertain future, such as the one forecast by the resilient approach (Bonß, 2016). Resilience has become increasingly important as cities have started fighting more (and more frequently) against the effects of climate change, while at the same time trying to counteract the effects of economic, social and political changes.

For the city, resilience means not only the ability to recover after suffering shocks, but also to reduce the impact of these shocks and to minimize the effort it puts into recovering, as well as the ability to face unlikely and unexpected situations. Usually, shocks that can affect big cities are severe and sudden events that have a powerful impact on their structures. In order to overcome them, a partnership between public, civil and private authorities is advised. When building and improving upon resilience, a rigorous urban and scenic planification is necessary, which in turn requires identifying the main processes and disturbances which the cities are likely to face, as well as identifying the frequency and intensity of these events (Vale and Campanella, 2005). One of the most common ways of improving resilience is biodiversity, to which we can add physical, social and economic diversity.

In recent years, the concept of resilience has become increasingly prominent, including in the field of urban geography (Muntele et al., 2018). This is due especially to the fact that cities nowadays must be able to not only withstand natural catastrophes (earthquakes, floods, fires etc.), but also to overcome the daily challenges they face (traffic, pollution, energy waste etc.). The concept of resilience has only been recently introduced in scientific research specific to geographical analysis. This is because the global, national and local evolutions have an increasingly greater impact on regions in general and urban centres in particular. Ethymologically speaking, the term "urban resilience" comes from the Latin "resilio, -ire", which means "to jump back, to contract, to recoil, to ricochet" (Klein et al., 2003). On the other hand, resilience demands a new way of thinking about sustainability, as it directly depends on adapting to changes that are unexpected and unknown until the moment they come forth. In the literature in our field of interest, one of the most common definitions of resilience is: the ability of a regional economy to withstand, absorb or overcome an economic shock that is external to that region (Simmie and Martin, 2010). A second concept has been introduced alongside resilience - vulnerability. The two have become almost unexpendable when analyzing the way urban systems respond to stimuli caused by the changes, shocks and hazards an urban system faces. Although seemingly opposed to one another, the two concepts are strongly linked and complementary. Sometimes, resilience is synonimous to reducing vulnerabilities or to increasing the cities' ability to adapt to the changes they are submitted to. As a human and geographical subsystem, the city is submitted to eight types of vulnerabilities: economic, social, ecological, organizational, attitudinal-motivational, political, cultural, physical (Wisner, 2009). Starting from the various definitions given to resilience, we can say that urban resilience means the ability of urban systems to remain stable or to quickly recover when facing disturbances, as well as to adapt to changes. The mention must be made that the urban system is conceptualized as being complex and adaptable, as it is 
made out of socio-ecological and socio-technical networks that stretch on more than one spatial scale (Meerow et al., 2016).

Over time, the concept of resilience started being used more and more often in urban planning, so that today it is used frequently both in discourse and in literature, where it has become one of the academic attempts at evaluating a city's potential lifespan in the context of the transformation of economic, social and political structures imposed by the requirements of an increasingly uncertain and unpredictable future (Pelling, 2003). Conceptually speaking, urban resilience can be defined as the ability of a city or a system to oppose oncoming shocks or attacks of any nature (Agudelo-Vera et al., 2012). However, when considering the complexity of the functions of the urban system, the definition given by Resilience Alliance seems much bettersuited: the degree to which cities are capable of tolerating changes before reorganizing around a new set of structures and processes (...), a flexible society capable of adapting in the face of uncertainty, at the same time capable of capitalizing on future opportunities (Resilience Alliance, 2007). This definition somewhat changes the initial assumptions, in the sense that it is not compulsory for a system to return to its initial state or a state of balance, but instead is offered the possibility to adapt and transform to a state that will later allow it not only to work at optimal parametres, but also to survive future changes (Folk et. al., 2010).

For cities, resilience is all the more important as the shocks that urban centres face are many and different. As such, cities nowadays need to face not only climate changes, but also economic, political and social changes. In this context, urban resilience focuses on four major directions: ecological urban resilience, urban risks and a decrease in risks of disaster, urban economy resilience, promotion of resilience through urban governance institutions (Leichenko, 2011). Adapting and overcoming these shocks depends fundamentally on the measures adopted by urban centres, with the urban development policy being very important. In this context, urban architects, engineers and transport experts must take into consideration the permanent adaptability of the urban infrastucture so that it can withstand the challenges it faces, the most important being the numerical increase of the population and the frequent climate changes.

\section{RESEARCH RESULTS}

Despite the fact that a consensus has not yet been reached regarding the definition and measurement of urban resilience, two essential aspects have been agreed upon: 1 . cities must resist to a wider variety of shocks and stresses in order to withstand climate changes; 2 . in an effort to react to climate changes, resilience must be combined with urban development and sustainability (Leichenko, 2011).

One of the numerous shocks that cities must face is global warming and the climate changes it generates. This shock does not come by itself, but rather is usually accompanied by shocks of economic, ecological and political nature. Urban centres have the task of adopting the necessary measures to adapt to all these shocks and to surpass moments of crisis, which represent a true management challenge for the administration of cities whose duty is, among others, to manage urban development policies in order to withstand such challenges. When talking about the challenges posed by extreme meteorological phenomena, we can say that the resilience of cities is directly and strongly 
influenced by the quality of the buildings, the efficient territorial planification and the extent of urban infrastructure and services. We must admit, however, that, in order to successfully counteract extreme meteorological phenomena, an essential role is played by early warning systems on the one hand, and the existence of an efficient intervention system on the other.

As a whole, the urban resilience policy is a complex field that develops constantly and is characterized by a series of significant challenges associated to the systems of urban governance, political pressures, threats and changes the city has to face.

\section{CONCLUSION}

The first conclusion we can draw from this paper is that urban resilience is the concept that allows cities to search for and find systemic solutions in order to confront and overcome the vulnerabilities and risks they face.

The second conclusion is that the category of resilient cities can only include cities capable of evolving, planning and acting so that they are permanently ready to respond to the dangers they face.

The third conclusion is that resilient cities are clearly superior to non-resilient cities when it comes to durable development and protecting their inhabitants.

The final conclusion is that it is imperious for policies that focus on long term urban resilience to take into account the future characteristics of cities and strive to achieve the objectives of resilience on a daily basis, not just when facing a disaster.

\section{Acknowledgement}

This work was supported by a grant of Ministry of Research and Innovation CNCS - UEFISCDI, project number PN-III-P4-ID-PCCF-2016-0166, within the PNCDI III project "ReGrowEU - Advancing ground-breaking research in regional growth and development theories, through a resilience approach: towards a convergent, balanced and sustainable European Union".

\section{REFERENCES}

Agudelo-Vera, C. M., Leduc, W. R., Mels, A. R., \& Rijnaarts, H. H. (2012). Harvesting urban resources towards more resilient cities. Resources, conservation and recycling, 64, 3-12.

Bogunovich, D. (2009). From planning sustainable cities to designing resilient urban regions. Sustainable development and planning IV, 1, 87-96.

Bonß, W. (2016). The notion of resilience: trajectories and social science perspective. In New perspectives on resilience in socio-economic spheres (pp. 9-24). Springer VS, Wiesbaden.

Donovan, A., \& Oppenheimer, C. (2015). Resilient science: The civic epistemology of disaster risk reduction. Science and Public Policy, 43(3), 363-374.

Folke, C., Carpenter, S., Walker, B., Scheffer, M., Chapin, T., \& Rockström, J. (2010). Resilience thinking: integrating resilience, adaptability and transformability. Ecology and society, 15(4).

Harvey, D. (1996). Justice, nature and the geography of difference. Oxford: Blackwell.

Klein, R. J., Nicholls, R. J., \& Thomalla, F. (2003). Resilience to natural hazards: How useful is this concept?. Global environmental change part B: environmental hazards, 5(1), 35-45.

Leichenko, R. (2011). Climate change and urban resilience. Current opinion in environmental sustainability, 3(3), 164-168.

Meerow, S., Newell, J. P., \& Stults, M. (2016). Defining urban resilience: A review. Landscape and urban planning, 147, 38-49.

Muntele, I., Ungureanu, A., Rusu, C. (2018). Spațiul geografic românesc la 100 de ani de la Marea Unire, Editura Universității "Alexandru Ioan Cuza", Iaşi.

Pelling, M. (2003). The Vulnerability of Cities: Natural Disasters and Social Resilience. London: Earthscan Publications Ltd. 
Resilience Alliance. (2007). Urban Resilience Research Prospectus: A Resilience Alliance Initiative for Transitioning Urban Systems Towards Sustainable Futures. Australia/USA/Sweden: CSIRO/Arizona State University/Stockholm University.

Simmie, J., \& Martin, R. (2010). The economic resilience of regions: towards an evolutionary approach. Cambridge journal of regions, economy and society, 3(1), 27-43.

Vale, L. J., \& Campanella, T. J. (2005). The resilient city: How modern cities recover from disaster. Oxford University Press.

Wisner, B. (2009). Vulnerability în International Encyclopedia of Human Geography, Elsevier, vol.12, 176 - 182.

Submitted: January 10, 2019
Revised:

February 28, 2019
Accepted and published online: March 29, 2019 